\title{
NEW ARCHITECTURES TRANSFORMING THE URBAN LANDSCAPE
}

\author{
R. PAPAGEORGIOU-SEFERTZI
}

School of Architecture, Aristotle University of Thessaloniki, Greece.

\begin{abstract}
In this digital epoch and information society, current thinking and research in architecture seems to be significantly transformed. The digital means and digital architecture reveal not only a different way of representation but also a different way of thinking, generating and materializing space and form. These new concepts, techniques and processes of design break the existing codes of modern architecture and introduce new ones. In the search for a unifying architectural discourse, this article examines three aspects of recent and current projects, which overturn previous morphology. Namely: topography, i.e. the relationship between a building and its site, the surfaces, i.e. the visible skin of the buildings, and hyper-projects, i.e. hybrid mega structures that mix private and public urban life. In terms of topography, the surface of the earth seems to move and extend itself in complex curvatures through buildings. These complex geometries, borrowed from physics, supersede the customary distinction between object (building) and site. As far as surfaces are concerned, the old dialectics between supports and weights are abandoned for continuous surfaces that are folded, curved or layered. Finally, recent hyper-projects form a kind of paradigm of the metropolis itself, superseding the old distinction between private and public space. These architectural metamorphoses point to a new paradigm shift.

Keywords: digital architecture, flow, folds, hyper-projects, organic, smooth, surfaces, topography.
\end{abstract}

\section{INTRODUCTION}

Contemporary cities, in the context of intercity competition to invite mobile capital and tourism try to acquire a distinctive 'physiognomy' and place identity in the global urban system. In this respect, 'built heritage' and 'innovative design of space' represent key morphological means for 'branding' the urban landscape [1].

Our interest lies in the innovative design and in particular in the avant-garde architecture of today. Leafing through international architectural magazines, one gets the impression that there is no formally recognized style but simply numerous parallel and sometimes just trendy currents and movements. At the same time, the 9th International Architecture Exhibition in Venice Biennale - the major architectural event of 2004 - also exhibited tangible and vibrant expressions of an architectural pluralism.

In terms of morphology buildings with organic forms and continuous surfaces generate surprise and delight. Even when the form is more traditional, i.e. using Euclidean geometry, one gets the impression that every ordinary or extraordinary building material can be used for facades. Building surfaces - skins - seem to become the focus of attention. As Christian Schittich [2] comments, 'our fast moving information age which is characterized by constantly changing fashions and a host of glittering coloured images, seems to have a great impact on architecture. It is fascinating to observe the different ways in which architects respond to these stimuli. Some accept the situation and react with equally colourful screen-printed images or bold, coloured patterns on the surface of glass, or create media facades and illuminated screens. Others rediscover the virtues of traditional materials like stone, wood or exposed concrete to demonstrate the physical presence of a building in a world increasingly dominated by virtual reality.'

Of this architectural plurality one can identify two major trends, each one with different architectural innovations. The first one continues more or less the architectural tradition of modernism in 
terms of basic principles concerning form and space organisation, the use of Euclidean geometry, and the representation of space in the Cartesian grid, and introduces innovations concerning the use of new materials, media facades, new construction methodologies, proposing smart and creative minimalist architectures of high and/or low tech. The second trend proposes a new architectural approach which breaks with all the modernistic codes, introduces new concepts of space and form organization, new morphologies, new materials, new ways of construction and new technologies. Our attention will be focused on this trend.

How are these architectures conceived? What is the source of their inspiration? Is there some unifying architectural discourse, and if so what is its distinctive character? Does it outline a new architectural paradigm?

To answer these questions, three aspects of architectural design are selected to be examined, because, in a clear manner, they overturn previous morphology: topography, surfaces and hyperprojects.

\section{TOPOGRAPHY}

The principle of engagement between architecture and landscape has always concerned architects. Buildings have been tied to site and its larger context, even during Modernism when this relationship was questioned. The notion that a building alters the conditions of its site and that the site exercises power over the building has brought modernists and advocates of genius loci to the acceptance that both buildings and site are affected in such a way that a third condition is created.

During the 1990s, numerous projects aiming at a kind of co-mingling of buildings and site in an inseparable way established new concepts of topography. These concepts range from the "bits" of computer technology to the contours of the landscape and affect not only botanical gardens, quarries, rehabilitated industrial areas of the cities, shorelines and public parks, but also museums, theatres, public markets, and even private residences.

'The surface of the earth moves and extends itself through buildings that stimulate our delight. Topology and fractal geometry are used to create more complex curvatures than those hyperbolic and elliptical forms of the Baroque, with equal lack of objective necessity or theoretical equivalence', as Kurt Forster [3] notes.

Topographically conceived buildings do more than supersede the customary distinction between object and site; they also reveal a different structure within themselves. Their infinite gradients and continuities suggest a new architectural paradigm. Among the many characteristic examples few illustrate the above features.

Eisenman [4] architects mark 'the shift of the new millennium away from the representationobsessed semiotic culture of the previous century to a new tactile, plastic and mobile culture of affect'. Their project for the 'Ciudad de la Cultura de Galicia' in Santiago de Compostela, Spain (1999-present), represents a tactile response to a new social logic: that of genetic coding. The genetic sources of their project are the scallop shell - the symbol of Santiago - and the plan of the old city centre. 'The ancient symbol is injected over the medieval centre with its Cartesian figure/ground urbanism and placed on the site. The trajectories of the new pilgrimage routes merge with the initial grid and with the site's topography deforming both grid and corresponding streets and buildings, while generating completely new forms in the landscape.' A powerful figure/figure urbanism is created, rather than considering the project as a series of discrete buildings. The buildings are incised into the ground, thus merging architecture and topography in one landscape (Fig. 1).

Paul Andrew's project for the National Grand Theatre in Beijing, China (2005), is another example of a tactile architecture of effect whose source of inspiration is again nature. As the architects [5] point out: 'The project features a huge outer shell with a metallic appearance on the outside and a 
central glass structure shaped like a curtain. The building emerges like an island in the middle of the lake surrounded by landscaped parks. The main access to the theatre is via an underpass under the lake.' This building is not incised into the ground but is in the water of an artificial lake and under it (Fig. 2).

Vincent Gualland [6] proposed an artificial mountain for a multifunctional centre in Denia, Spain (2002). The geological structure of the quarry - on the micro, medium and macro scales - as they say, guides their main choice: 'a crystalline geometry of hexagons becomes the base or the "gene" that will initiate the process of constructing the skin of the hill [Fig. 3]. A multifunctional centre with commerce, hotel and cultural activities will function under the hill. A variety of itineraries created on the surface will allow interior access from different points.' Here again a powerful figure/figure urbanism is created merging architecture and topography in the same landscape (Fig. 1).

The project of the atelier Jean Nouvel [7] for the Guggenheim Museum in Tokyo (2001) is inspired by the paradigm artifice-nature, one of the bases of Japanese culture: 'This is the cult of present; the revelation of the fleeting instant; the unconsciousness of passing time; the emotion of the season. Nature is a positive counterpoint to the urbanization of Tokyo. Artifice and nature are chosen as strategy for the alternative, which is so difficult to exist in the urban collage of Tokyo. The Temporary Guggenheim is a little hill, the hill of season: white-pink in the springtime, tender green for summer, flamboyant for autumn and grey as bark in winter. It shows itself as well by a large totemic mast,

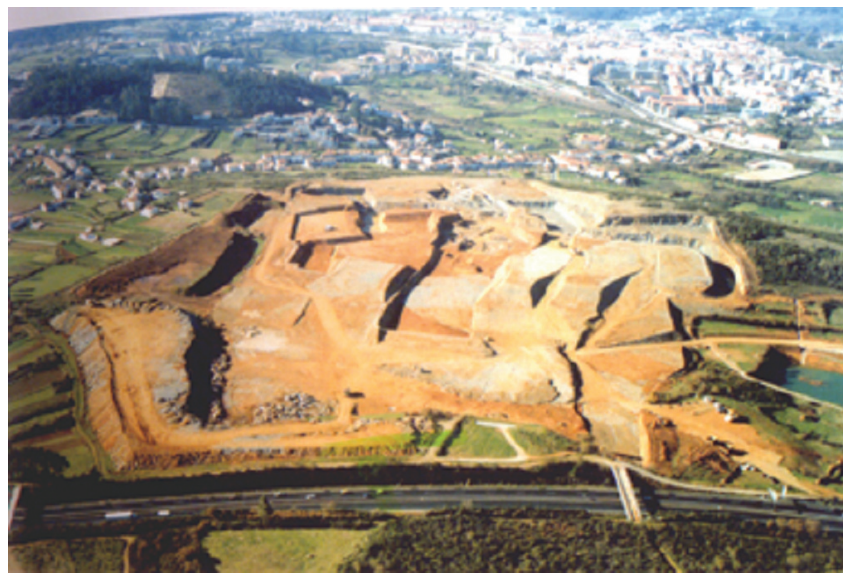

Figure 1: Peter Eisenman: Aerial view of the cultural city, Santiago, Spain.

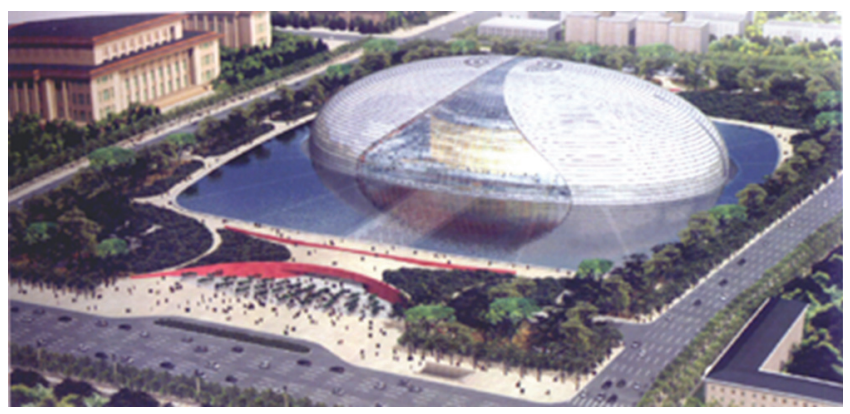

Figure 2: Paul Andrew: National Grand Theatre of China, Beijing (exterior view). 


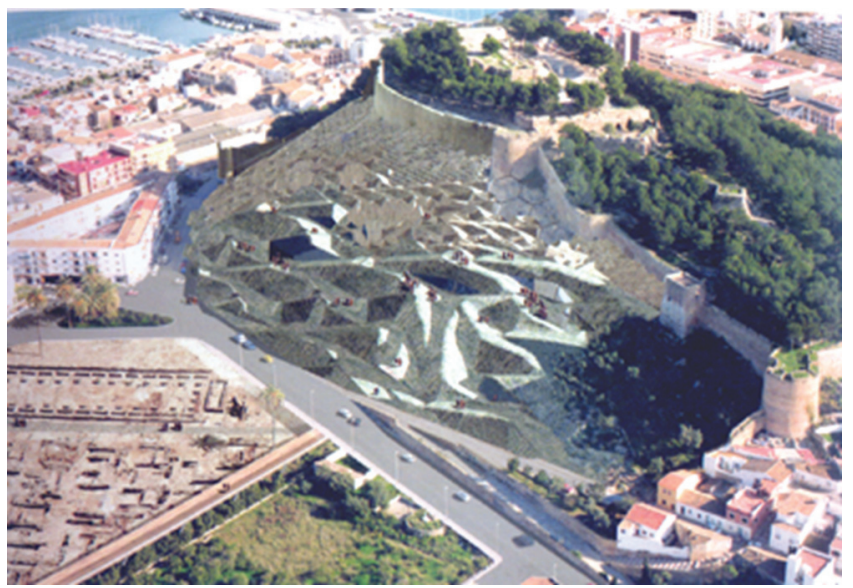

Figure 3: Vincent Gualland: Multifunctional centre, Denia, Spain.

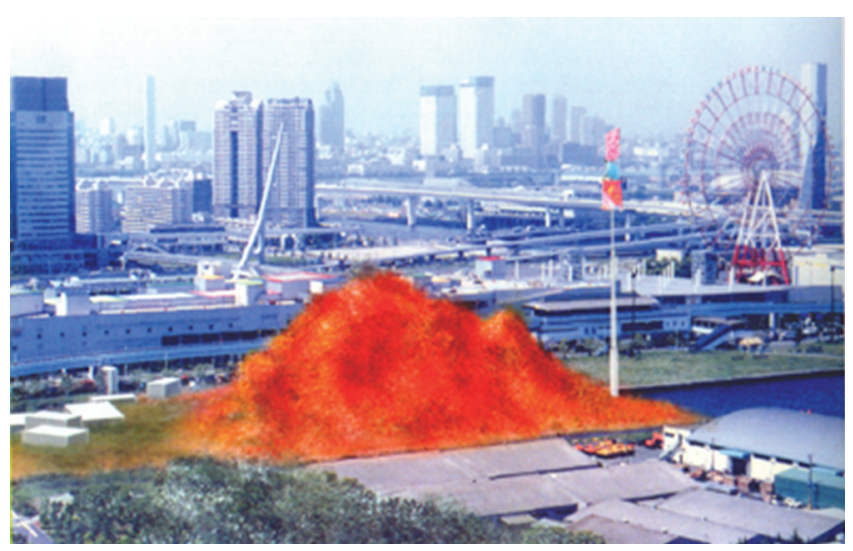

Figure 4: Jean Nouvel: Guggenheim Museum, Tokyo, Japan.

which turns three large lit images, slowly. It uses intrigue, mysterious and attractive, in order to become the icon of the new cultural life in Tokyo' (Fig. 4).

\section{SURFACES}

As Kurt Forster [8] points out: 'numerous recent projects and buildings are no longer based on the dialectic of support and weight but instead on continuous surfaces be they folded, curved or layered.' Contemporary designers approach the surfaces of products and buildings like human skin in terms of complexity and ambiguity in form.

According to Ellen Lupton [9], 'smooth exchange, flow, continuous surfaces, skin, membranes, and bubbles, signal a paradigm shift in the relationship between human and technology. The rise of digital media over the past decade has changed the practice of design, providing tools for making objects and buildings that resemble living creatures - modelled with complex curves and forms while remaining distinctly artificial. This new organicism has taken shape most aggressively across the surface of things. The primacy of the skeleton has given way to the primacy of skin', which means emphasis on the complexion, the appearance of things. Surfaces are not, as we often depict them, 
thin membranes that enclose spaces, but have their own depth, becoming dense, complex substances equipped with their own identities and behaviours. New materials react to light, heat, touch and mechanical stress. 'Translucency and mutability have replaced transparency and permanence. The outer envelope has detached from the interior volume. Flexible membranes are embedded with digital and mechanical networks. Thin planes of material are folded, warped, or pumped with air to become load-bearing structures.'

'Digital technologies that were used for the design of airplanes, ships automobiles, consumer products and/or cinema animation have been appropriated by architects to project new "bodies", new spaces, new architectures. Forms designed within the space of the computer are analogous to bodies moving in time. The area of digital technology that has a critical impact on design and architecture is the realm of NURBS (non-uniform rational Bezier spline) based3D modelling programs such as Alias, Catia, Rhinoceros, Pro/Engineer and Maya, which allow architects to work with complex curvatures in real time', as Alicia Imperiale [10] notes. These programs use algorithmic formulas to allow lines and surfaces to be adjusted and recalculated continually. New surfaces are embedded and developed in relation to the existing surface, while a change of scale in a part leads to the rescaling and the recalculation of the entire surface. Rather than conceiving the form as static, the new 3D modelling software programs allow the designer to work on the form that is constantly evolving and smoothly registering the continuously changing algorithmic parameters in 3D 'topological' surfaces before the designer's eye and through the designer's intervention.

The building skin is transformed to digital skin with organic, hybrid, flow and complex characteristics. Surfaces become continuous, smooth, luminous and flexible, looking more like sculptures rather than buildings. The source of inspiration is nature, especially biology, as one can see in the NOX Son-O-House [11], (Fig. 5) which looks more like a giant insect, and the proposal for Pusan, Korea by Xefirotarch [12], (Fig. 6) which looks more like a living creature than a building.

New synthetic materials with new properties are developed by methods like nanotechnology and biotechnology, to respond to the evolution of forms and new cultural demands. These materials besides reliance and plasticity move according to the requirements of the designer and/or user, react to environmental stimuli, think and repair themselves. They function like miniature computers loaded with the relevant database.

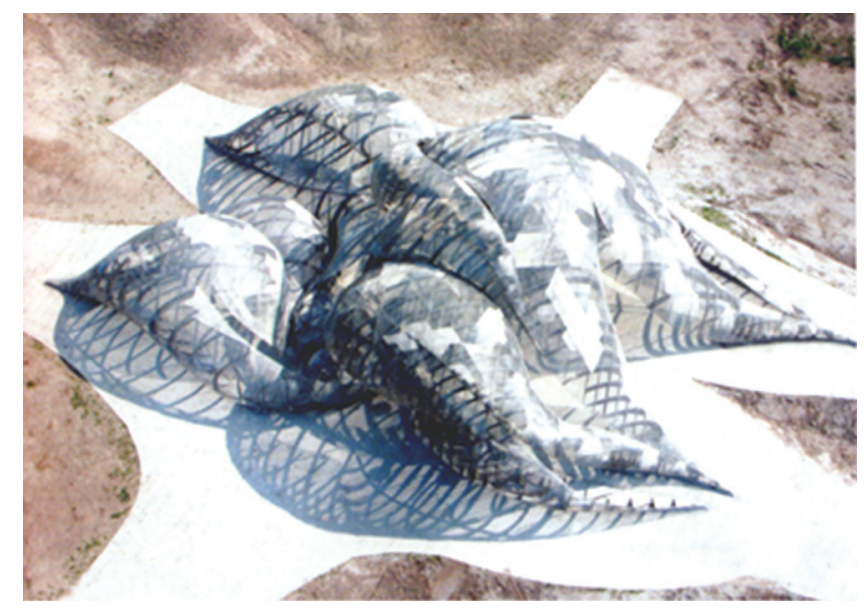

Figure 5: NOX: Son-O-House, Breugel, the Netherlands. 
The digital design of buildings has produced forms that can be classified as 'folds', 'blobs' and 'boxes'. However, these typologies are not stable, since a fold can evolve to a blob and/or a box and vice versa. As Joseph Rosa [13] notes, 'any avant-garde movement becomes more mainstream as its aesthetic characteristics become codified and formalized into defining principals, but the digital typologies of Folds, Blobs and Boxes have distinct characteristics that render them unique' (p. 25). A digital fold in architecture can be an entire building or an interior space that appears pleated like fabric or smooth with edgeless transitions between surfaces. A smooth fold creates a gentle transition and gives the appearance of a continuous surface that wraps a building or interior space.

A characteristic example of fold (entire building) is Diller and Scoffidio's [14] project for the Eyebeam Museum of Art and Technology (2001) (Fig. 7). They describe their spatial logic as follows: 'A pliable ribbon divides production from presentation. This ribbon undulates from side to side as it climbs vertically from the street. The floor becomes wall, turns into floor and so on.'

Another fold (internal and external space) is the project of Zaha Hadid [15] for the Centre of Contemporary Arts in Rome (2002). She describes it as 'walls/not walls'. A critique of museum walls is proposed through the wall's emancipation. 'The wall becomes the versatile engine for the staging of exhibition effects. In its various guises - solid wall, projection screen, canvas, window to the

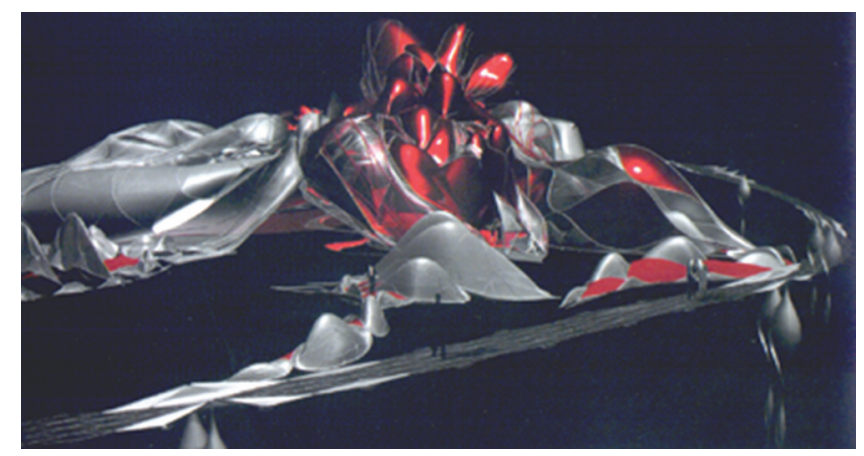

Figure 6: Xefirotarch: Pusan Metropolitan City, Korea international competition.

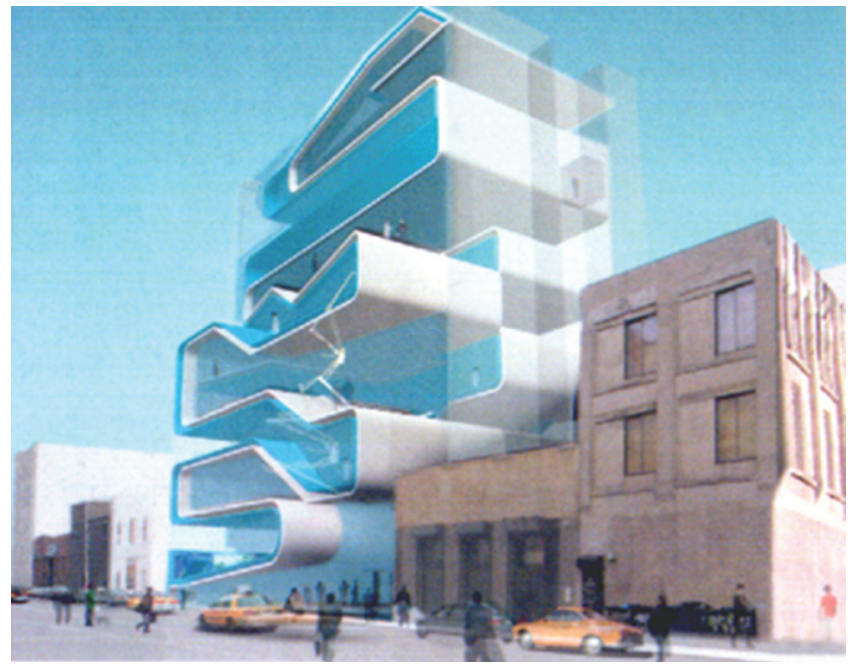

Figure 7: Diller and Scoffidio: Eyebeam Museum for Art and Technology Competition. 
city - the exhibition wall is the primary space-making device. By running extensively across the site, cursively and gesturally, the lines traverse inside and out. Urban space is coincidental with gallery space. Further deviations from the classical composition of the wall emerge as incidents where the walls become floor, or twist to become ceiling, or are voided to become a large window' (Fig. 8).

Finally, Eisenman's 1997 Staten Island Institute of Arts and Science (Fig. 9) in Staten Island, New York, 'is a model for a digital fold', as Rosa ([13], p. 34) points out. Designed to occupy a prominent site with views of Manhattan, the building will be also be part of a new ferry terminal for many commuters. Eisenman's studio used digital software to translate the various pedestrian and vehicular patterns of movement in the building into design. Collectively, these paths of circulation generate a series of folded exterior forms and interior spaces that convey the idea of fluidity and motion.

Blobs are made of subtle (pliant) curvatures resembling bubbles or drops. As Manuel Gausa ([16], p. 84) notes, the most interesting example of a class of topological geometric types that have been developed recently is the 'isomorphic polysurfaces' or what the special effects and animation industry is referred to as 'meta-clay', 'meta-ball' or 'blob' models. Their form is asymmetrical, sculptural and organic.

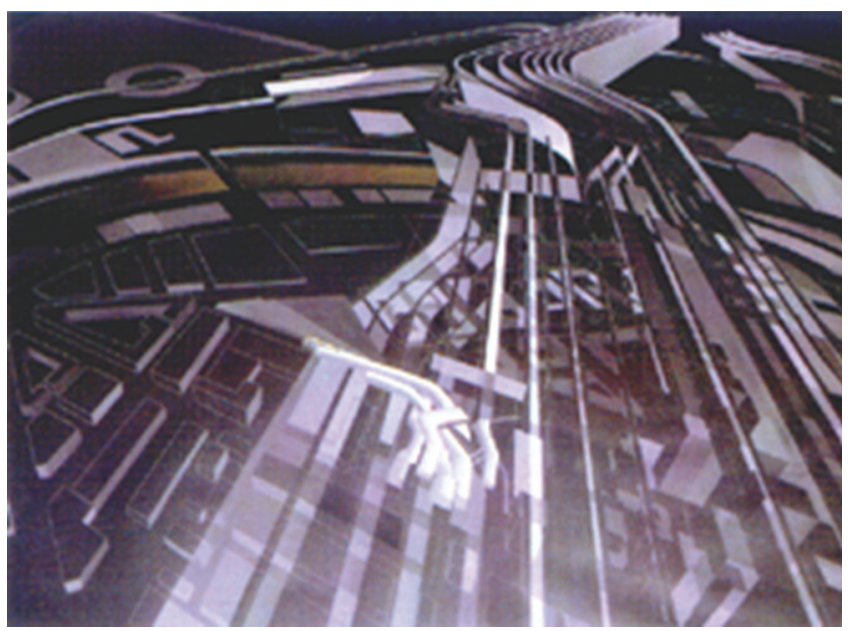

Figure 8: Zaha Hadid: Centre for Contemporary Art, Rome, Italy.

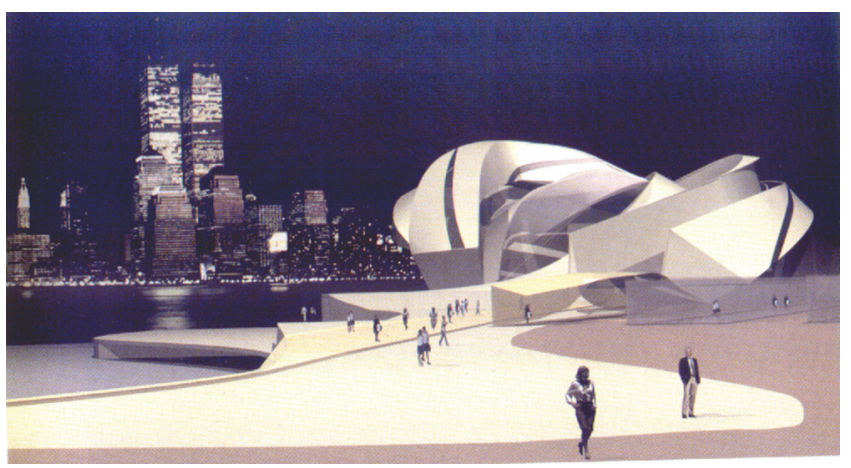

Figure 9: Peter Eisenman: Staten Island Institute of Arts, New York. 
The first digitally produced blob was the Water Pavilion for Delta EXPO 'Water land' 1997, made by NOX [17] in Zeeland, the Netherlands (Fig. 10). The building is a wavy, elongated blob sheathed in stainless steel. 'Its architecture was developed simultaneously with a highly innovative interactive interior with electronic interaction of light, sound and projections that fully involves all the senses in the visitor's experience.'

'The purest architectural blob', as Rosa ([13], p. 33) notes, is Frank O. Gehry's Experience Music Project (EMP) (Fig. 11) in Seattle, Washington (2000). On a site adjacent to the city's iconic Space Needle, Gehry's EMP is an interactive rock music museum. He first developed the design using physical models and then made the transition to digital. This building is a model for what digital blob architecture can be in the twenty-first century.

Frank O. Gehry's [18] last masterpiece for the 'Walt Disney' Concert Hall combines folds and blobs (Fig. 12). 'The focus of design is the 2,265-seat main concert hall, whose interior and form are a direct expression of acoustical parameters. The wooden walls and the sail like wooden ceiling forms give one the impression of being within a great ship inside the walls of the hall.' The exterior is clad in stainless steel panels. The building's orientation, combined with the curving and folding exterior walls presents highly sculptural compositions.

Digital 'boxes' are made by orthogonal forms, which are bent, twisted or curved. These digital manipulations enhance the architect's ability to analyze and respond to the programmatic needs of a project and design a structure that becomes integral to the site. For example, the building can be bent and twisted to take advantages of views, reflect topographic conditions, or conform to prevailing wind patterns.

Bernard Tschumi's recently completed (2002) School of Architecture (Fig. 13) is an excellent example of what the new digital box can be. Conceived to fit into an existing university campus environment, Tschumi's School of Architecture at Florida International University in Miami is a

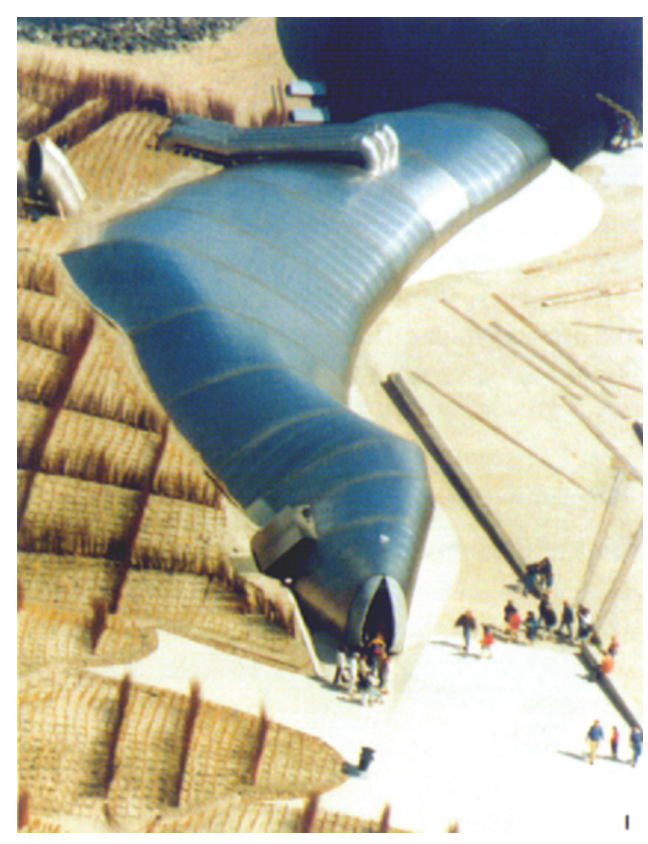

Figure 10: NOX: Water Pavilion, Zeeland, the Netherlands. 


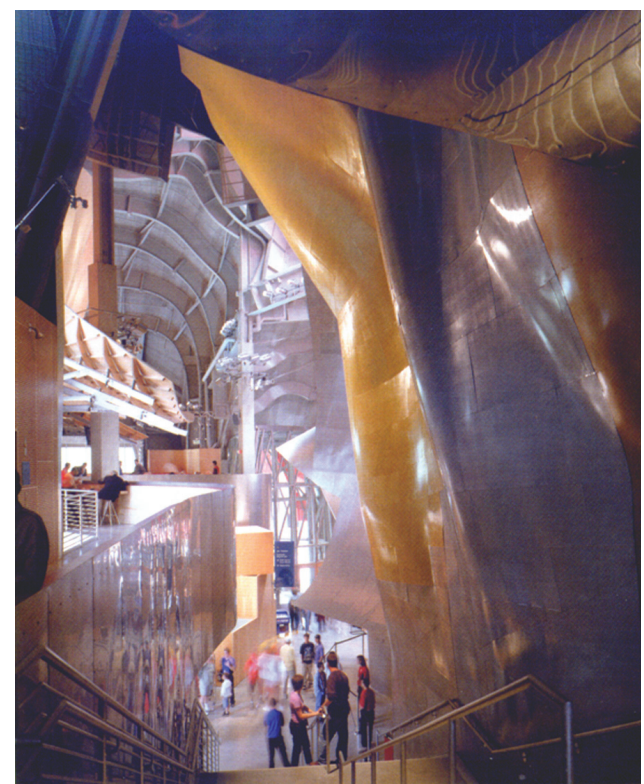

Figure 11: Frank O. Gehry: Experience Music Project, Seattle.

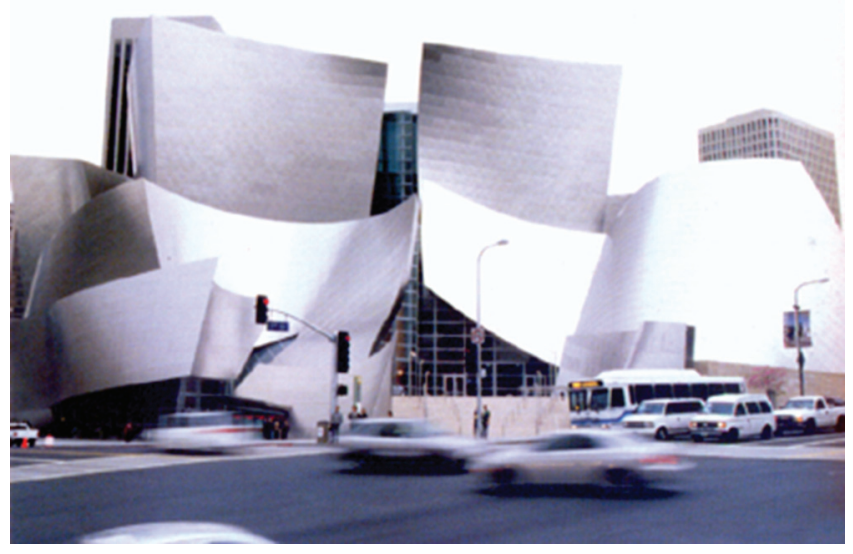

Figure 12: Frank O. Gehry: Walt Disney Concert Hall (exterior), Los Angeles.

large complex of buildings totalling 90,000 square feet. The overall plan responds to the movement of its future users, deflected wind patterns, and the buildings' functional programs. Tschumi developed the warped and irregular surfaces seen in the canted and twisted forms of the yellow and red generators using 3D software. 'The result is a complex of buildings that will have a distinctive yet contextual presence in the overall setting of post-World War II Modern architecture', as Rosa ([13], p. 34) remarks.

Finally, another characteristic example of a digital box is the Jinling tower for Nanjing, China (2003) by Skidmore, Owings \& Merril [19] (Fig. 14). As the architects point out 'this project seeks to create an iconic landmark that will position Nanjing among China's most prominent cities'. The tower is divided into four quadrants, which rotate $90^{\circ}$ over the height of the tower. In plan therefore, 


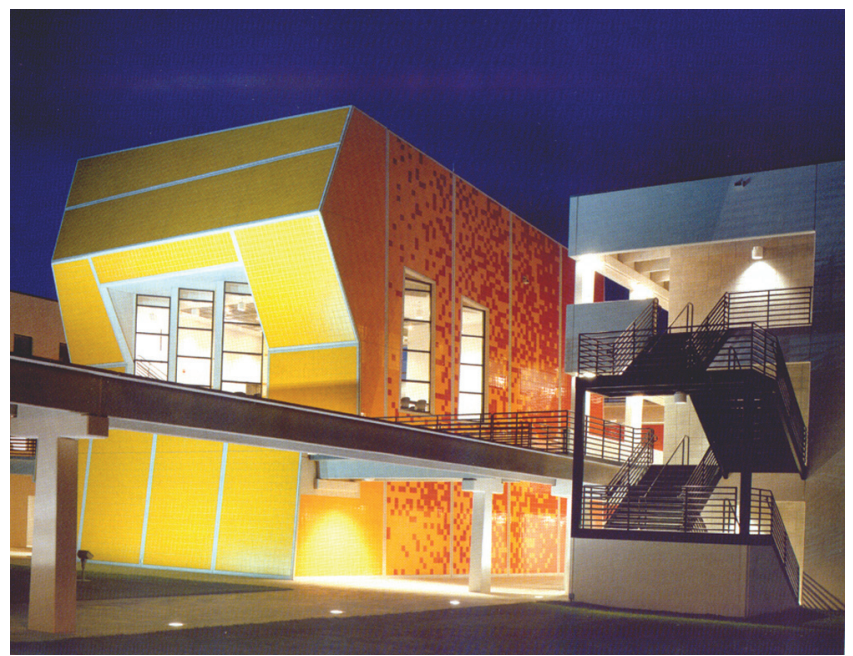

Figure 13: B. Tschumi: School of Architecture, Miami, Florida.

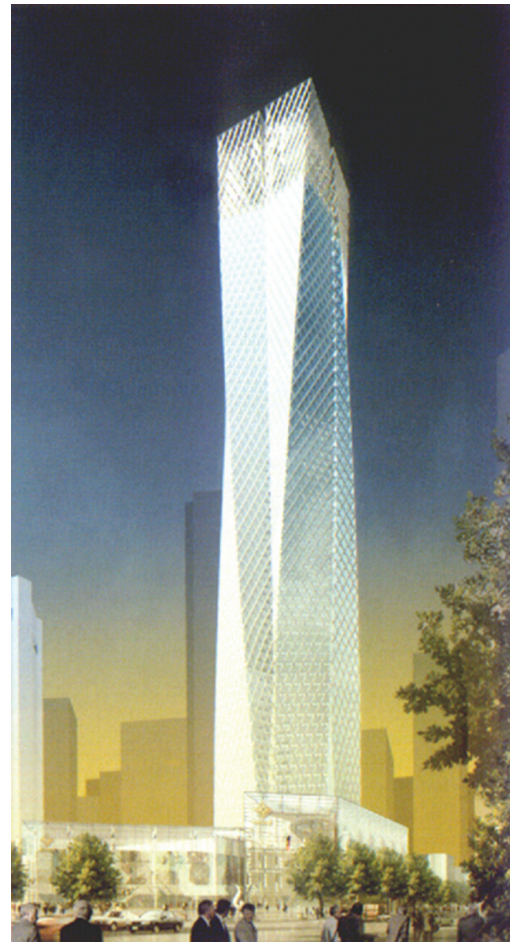

Figure 14: Skidmore, Owings \& Merrill: Jinling Tower, Nanjing, China.

the tower begins and ends as a square, shifting to an ' $x$ ' in the middle levels and as the quadrants twist, exposing more perimeter surface. This shift corresponds to the changing of uses: hotel and offices occupying the large square floor plates at the top and bottom, respectively, while apartments take advantage of the separation and increased opportunities for view afforded by the x-shaped floor plates. 


\section{HYPER-PROJECTS}

Recent projects at nodal points of the metropolis appear to draw on virtually both previous categories: they conjoin site and structural frameworks into new topographies, or when erected as high-rise buildings, they take forms made of smooth organic surfaces as previously mentioned. As Kurt Foster [20] notes, 'their characteristic hybrid of activities, spaces and publics make for experiences that periodically dilate and refocus attention inviting by calculated distraction and gratifying by both their surprises and their neutrality. They form a kind of paradigm of metropolis itself, hence their site tends to be enormous, their internal physiology staggeringly complex and their life parasitic of the city they replicate.'

Maybe the first mega-structure falling to the category of surfaces and hyper-project is the 'Max Reinhardt Haus' proposed by the Eisenman [21] team for Berlin (1992). This 34-storey building emerges from the urban landscape as a landmark. It is a prismatic form that folds in on itself while simultaneously opening out to infinite possibilities of its urban context. Comprising a range of activities for body and mind-hotel, fitness clubs, office space, a sports and game centre, film and video auditoriums, press agencies, and restaurants it responds to contemporary demand for such media centres. 'This building, which originates its form from the Mobius strip, presents a unified structure that separates, compresses, transforms and then rejoins itself horizontally at the roof level. In this way it denies the traditional dialectic of inside and outside and blurs the distinction between public and private', as the architects note (Fig. 15).

Another famous mega-structure falling into the category of topography and hyper-project is the Yokohama Port Terminal (1996-2002) (Fig. 16) by Foreign Office Architects (FOA) [22]. By abandoning the typology of terminal stations they conceived their building as an extension of the surrounding urban space, which was given priority. As the architects point out, 'the building was designed as an interface between two social machines: the public urban spaces and the passengers' movement

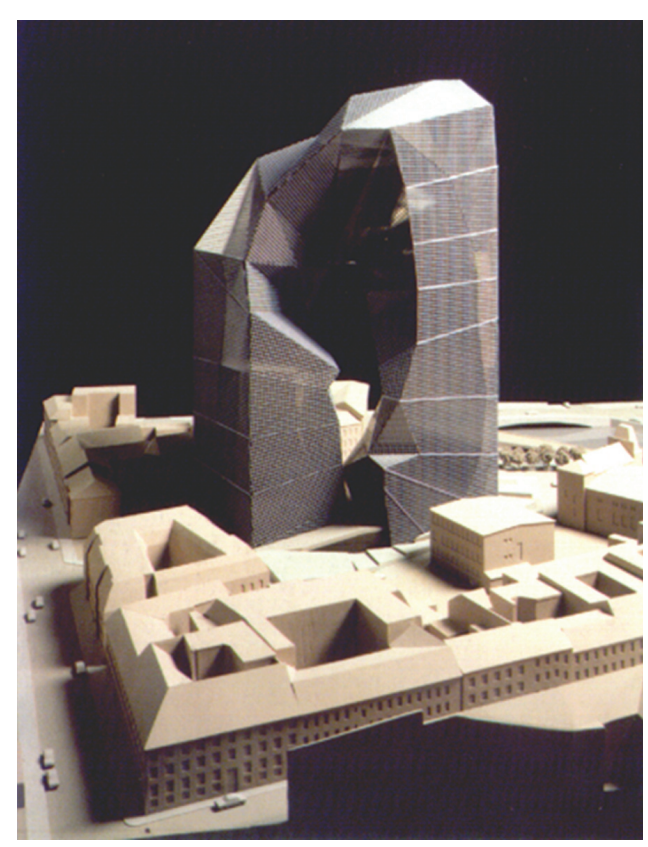

Figure 15: Peter Eisenman: Max Reinhardt Haus, Berlin, Germany. 


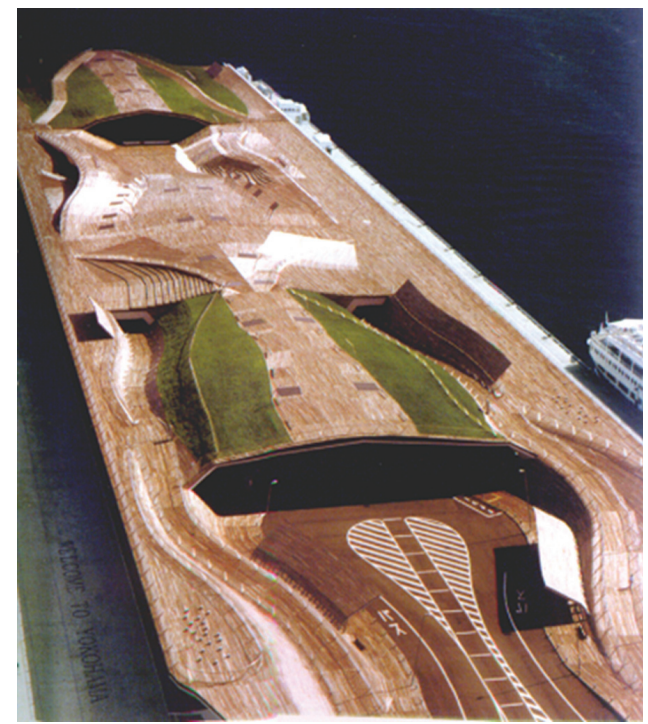

Figure 16: Alejandro Zaera and Farshid Moussavi: Sea terminal, Yokohama, Japan.

in the terminal'. Thus the space becomes fluid, continuous and multidirectional. The demands of the program are organised in 3D strips that fold to create cavities for different activities. Through movement in space, one gets the feeling that the relationship between the building and ground is constantly changing and their limits are blurred. The urban park on the roof enters the terminal spaces thus breaking the limits between the interior and the exterior. Ground and structure make an inseparable unity. To achieve this built folded form, FOA used ship-building techniques to produce massive building sections. From conception to construction, the Yokohama Port Terminal illustrates that invention coupled with digital technology and production can result in a new architecture and in one of the most important built examples to date.

UN Studio [23] in their master plan for the station area of Arnhem, the Netherlands (1996-2007) proposed a coherent plan, which comprises $80,000 \mathrm{~m}^{2}$ of office space, $11,000 \mathrm{~m}^{2}$ of shops, 150 housing units, a new station hall and a parking garage for 1000 cars and 5000 bicycles. The station area forms the main entrance to the town (Fig. 17). This accentuates the need for good connections to the old centre and good urban quality for the people, who work, wait, change buses or trains, meet, and shop daily. As the architects note, 'the Arnhem transfer zone focuses on finding overlapping areas of shared parameters and common values. The shared element is pedestrian movement, which concerns every party involved in the redevelopment of the location. Movement studies are therefore the cornerstone of the proposal'. This study was possible because of the algorithmic software that the team developed. The main visual attraction of the Arnhem Central is the Terminal Hall which rises, bends and folds onto itself to create an event space that is experienced by almost everyone who traverses this complex. To generate this digitally feasible form, the architects used the analogy of the 'Klein bottle' diagram to conceptually integrate the multiple conditions that fold through the public space, generating one singular form for Terminal Hall.

Usually museums are considered to be well guarded, close places which open to the public for certain hours during the day and sometimes certain days during the week. Nevertheless, as we have already seen in the proposal of Zaha Hadid for the 'Centre of Contemporary Arts' in Rome, the urban space is coincidental with the gallery space. The same applies for the 'Musee de Confluences' by 


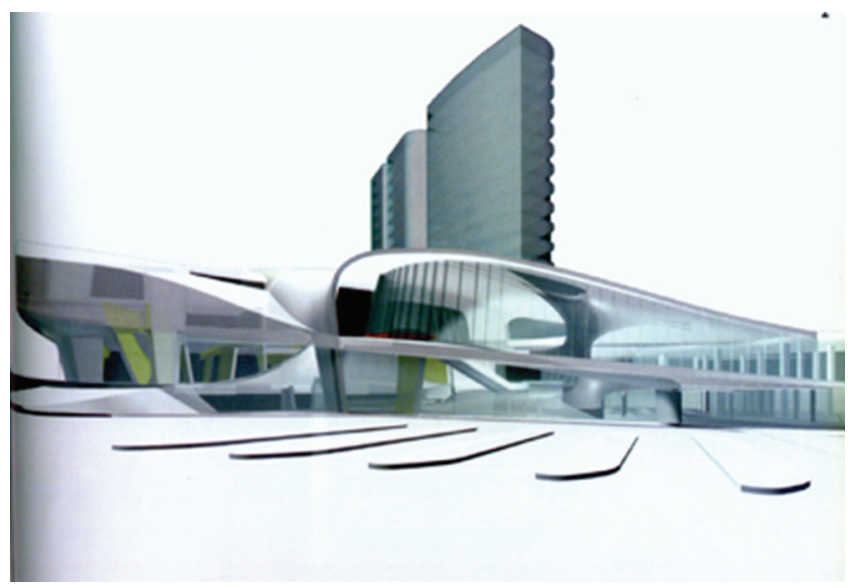

Figure 17: UN Studio: Station area, Arnhem, The Netherlands.

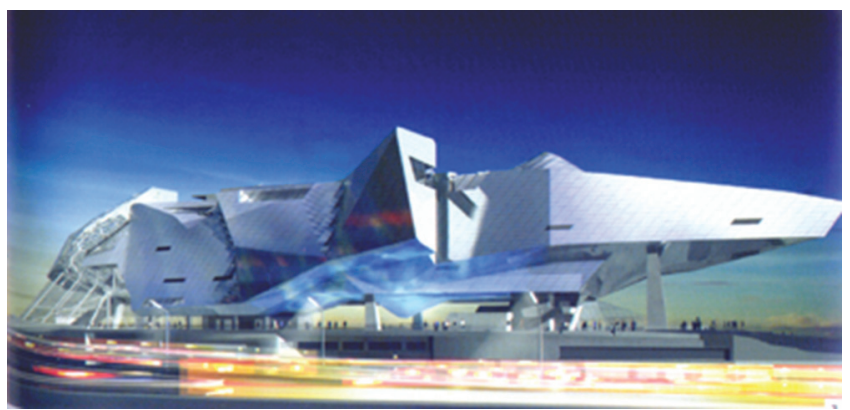

Figure 18: Coop Himmelblau: Musee des Confluences, Lyons, France.

Coop Himmelblau [24] in Lyon, France (2001-2007). The architects present their project as follows: 'Mutations of form, penetrations, deformations, simultaneities, breakdowns and variability have an effect on architecture. The resulting architecture is characterised by the interactions, the fusion and mutation of different entities constituting a new shape. This museum provides access to the knowledge of our age. Stimulating a direct and active use, it is not a museum site but also a venue in town. The architecture hybridises the typology of a museum with the typology of an urban leisure space. As an extension of the park located on the southern top of the island a new urban space formulates itself; a landscape consisting of ramps and surfaces merging the inside and the outside in a dynamic sequence of spatial events' (Fig. 18).

The West Side Convergence Project for New York (1999) by Jessie Reiser and Nanako Umemoto was a submission for the design of cities competition, sponsored by the International Foundation for the Canadian Centre for Architecture (IFCCA), which conveys the impression of a vast natural landscape punctuated by skyscrapers. Their proposal assumes a Manhattan site, spanning the area from 30th to 34th Streets and from Eighth Avenue to the West Side Highway. Close examination reveals a design for an enormous structure comprised of multiple levels. The upper level includes an interior park, while the lower provides access to trains, as well as discretely located concessions and commuter conveniences. 'The vast rolling space-frame roof visually reads as an unfolding landscape', as Rosa ([13], p. 29) notes (Fig. 19). 


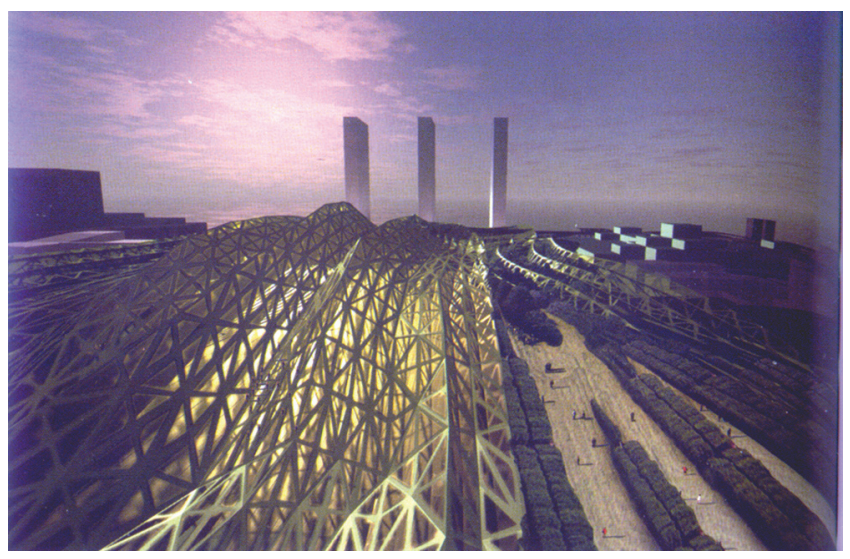

Figure 19: Reiser and Umemoto: West Side Convergence Project, New York.

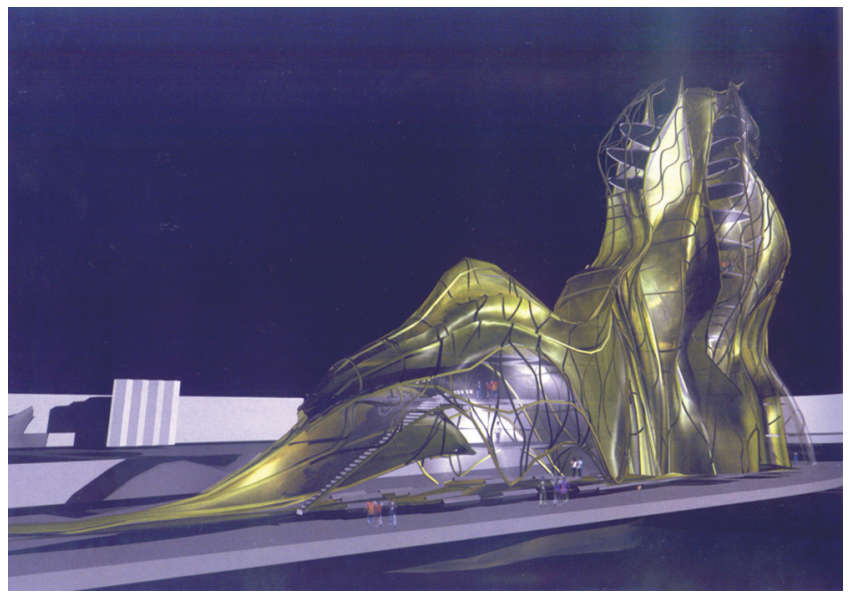

Figure 20: Xefirotarch: U2 Tower, Dublin, Ireland.

Finally, the U2 Tower competition proposal by Xefirotarch 'signifies the trajectory that architecture can achieve when digital literacy and fluid thinking merge', as Rosa ([13], p. 80) remarks. This biomorphic multi-use tower solution also blurs defined programming. The top of U2 Tower's canted prow is a recording studio, while the lobby-situated on the ground floor-is porous to the city and acts like an enclosed 'public square'. The U2 Tower's intricate structural system is filled with mostly live/work spaces that vary in configuration to reflect the realities of heterogeneous social interaction (Fig. 20).

\section{CONCLUSION}

The examination of topography, surfaces, and the complexity of hyper-structures of recent architectural projects, buildings, and urban landscapes illustrates a new conceptualisation of space, form, and order and a new architectural discourse that overturns the existing codes of modern architecture.

In cultural terms, as Alicia Imperiale [10] notes, 'There has been a movement away from dialectic relationships, from the opposition between surface and depth, in favour of an awareness of the 
oscillating movement from one into the other.' Merging 'figure-figure' topographies, folding between exterior and interior surfaces, hybrid multi-functional hyper-projects signal a paradigm shift from previous architectural language.

The impressive global dispersion - as presented in the 9th International Architecture Exhibition of Venice Biennale - of implemented architectural projects that strained to be labelled as 'liquid', 'merging', 'folding' or any other architectural manifestation of 'hyperspace' points to the fact that digital topographies are not a reflexive matter, a play of words concerning only the academia or the architectural press. 'Nor does it appear that the new paradigm is in danger of consuming itself before it has had the chance to reach the masses as it happened with the architecture of deconstructivism', as Lois Papadopoulos [25] notes. On the contrary, it seems that this plurality of outcomes has already constituted a new architectural paradigm, which has acquired a significant share of the built universe in a short time.

The passing over from the 'deconstructive' thought of Jacque Derrida to the 'differentiated' thought of Gilles Deleuze, transformed previous concepts of space and time. Architects have appropriated many terms and concepts from Deleuze's [26] work 'The Fold': affiliation, smooth and striated space, folding, and pliancy. The incorporation of these terms, which Deleuze developed to describe baroque aesthetics and thought, into architectural practice has led to significant changes in how buildings are thought of in relation to the environment. The Deleuzean thought has promoted smoother transitions and interactive exchanges across surfaces through serendipitous, temporary links that exist within buildings and sites. The fold is ambiguous, being figure and non-figure, somehow formless.

On the other hand, the design of smooth form has been facilitated by the 3D modelling software. From this point of view, the use of digital technologies had a liberating effect on architectural form. Organic architectures that register the infinite variations and mutations from their evolutionary growth can be turned to buildings. As Alicia Imperiale [10] remarks, 'these sinuous curvatures and warped surfaces wrap around the inhabitants like a second skin. The elision between the inhabitant and the architecture, between the object and the user, the landscape and the building is symptomatic of our time'.

Either as form or as process, the fold is the unifying main characteristic of the new architectural discourse. This new design strategic takes its distance from the Euclidean geometry and the distinct volumes of modern architecture and uses the topological perception of form with continuous curvatures as its ultimate expression.

As a result, the old dichotomising divisions which, for many years, were paradigms of our ideological and disciplinary baggage - interior/exterior, solid/void, building/site, figure/ground, support/weight, natural/artificial, public/private, order/chaos, determinate/indeterminate, formal/informal, particular/general, open/closed, etc. - have been abandoned and replaced by fusions, mixed actions and principles associated with the capacity for hybridization and transfusion. 'These fusions of former dichotomies', as Manuel Gausa ([16], p. 25) remarks, 'do not seek to construct through contradiction compositions but rather through interactions capable of reconciling-of making coexist-in the same hybrid framework twin phenomena, the more paradoxical the more, apparently, impossible'.

The focus of attention is centred on the surface, either made of building materials, or ground-in the case of landscape buildings. As Alicia Imperiale [10] comments: 'when using NURBS-based software, one creates an object by connecting one surface to another. The surface, skin, and interface of architecture is emphasized, instigating a more technical, performative, programmatic, and environmental way of thinking, one that has its roots in the language of building. Yet there is a superfluous character of interior space that results from placing so much emphasis on the design of the architectural skin and its supporting structure. While the design of a sinuouous architecture theoretically seeks to smooth distinctions between the exterior and interior, this division is actually heightened. 
There is a risk of the architectural interior becoming merely the leftover space of a highly articulated blob exterior.' This criticism does not apply in the examples presented above and for most of the avantgarde architecture, but it could apply when these new architectures will become widely implemented by the mainstream of architects.

Another criticism could refer to the relationship between old and new urban landscapes in metropolitan or smaller cities. The examples of blobs, folds, or digital boxes of the avant-garde architecture were proposed, or built on prominent sites and acted almost always as landmarks in the cityscape, with renovating and very appealing effects for the cities that acquired them. What kind of relationship between old and new would be created if blobs, folds or deformed boxes were multiplied in great numbers in an existing urban landscape?

The desire to make a smooth architecture ties into a broader cultural discussion. The concepts of smooth exchange, flow, continuous surface, skin, membranes, bubbles are ever present in contemporary culture from animation to economics. Three-dimensional digital modelling software plays a great role in this discussion. It can be used to design a handheld consumer object or an urban-scale intervention. This sliding scale in digital continuum equalizes previously distinct cultural artefacts. What results is a strange fetishism of the consumer object, an emphasis on the intimate interface between technology and the living body. As Imperiale [10] remarks: "it is the moment where the terror of the technological is softened through smooth contours between our hands and the objects we use and the architectures and urban surfaces that surround us'.

However, the new generation of architects does not feel the terror of technology. On the contrary, as Neil Spiller [27] writes, 'most of them, want that the viewers and users of their design interact, inform and respond to the designs given to them'. They want to understand the multi-scaled ecologies of our world and work with them. Their aim is to achieve a sustainable, healthy world with technology and not without it.

Since the merciless quest of form is always the condition on which architecture bases its existence, let the future search for forms have an ecological concern. In an age when raw materials are becoming scarcer and problems of growing $\mathrm{CO}_{2}$ emissions are increasingly apparent, this approach provides scope for design that is keeping with the times without the danger of degenerating into mere formalism.

\section{REFERENCES}

[1] Beriatos, E. \& Gospodini, A., 'Glocalising' urban landscapes: Athens and the 2004 Olympics. Cities, 21(3), p. 189, 2004.

[2] Schittich, C., Between fashionable packaging and responsive skin: trends in modern façade design. Detail, 7/8, pp. 754-760, 2003.

[3] Forster, K., Topography. Metamorph - 9th International Architecture Exhibition, Trajectories, Venice Biennale, Rizzoli: New York, p. 141, 2004

[4] Eisenman, P., Ciudad de la Cultura de Galicia, Santiago de Compostela, Spain. Metamorph9th International Architecture Exhibition, Trajectories, Venice Biennale, Rizzoli: New York, p. 185, 2004.

[5] Andrew, P., National Grand Theatre of China, Beijing. Metamorph - 9th International Architecture Exhibition, Trajectories, Venice Biennale, Rizzoli: New York, p. 61, 2004.

[6] Guallart, V., Artificial mountain for a multifunctional centre, Denia, Spain. Metamorph - 9th International Architecture Exhibition, Trajectories, Venice Biennale, Rizzoli: New York, p. 163, 2004.

[7] Nouvel, J., Guggenheim Competition Project, Tokyo, Japan. Metamorph - 9th International Architecture Exhibition, Trajectories, Venice Biennale, Rizzoli: New York, p. 182, 2004. 
[8] Forster, K., Surfaces. Metamorph - 9th International Architecture Exhibition, Trajectories, Venice Biennale, Rizzoli: New York, p. 225, 2004.

[9] Lupton, E., Skin: new design organics. Skin, ed. E. Lupton, Princeton Architectural Press: New York, pp. 29-41, 2002.

[10] Imperiale, A., Digital skins: the architecture of surface. Skin, ed. E Lupton, Princeton Architectural Press: New York, pp. 55-63, 2002.

[11] NOX (Lars Spuybroek \& Kas Oosterhuis), Son-O-House, Son en Breugel, The Netherlands. Metamorph - 9th International Architecture Exhibition, Trajectories, Venice Biennale, Rizzoli: New York, p. 72, 2004.

[12] Xefirotarch (Herman Diaz Alonso), Pusan metropolitan city, Korea, international architectural competition. Metamorph - 9th International Architecture Exhibition, Trajectories, Venice Biennale, Rizzoli: New York, p. 73, 2004.

[13] Rosa, J., Next Generation Architecture: Contemporary Digital Experimentation and the Radical Avant-Garde, Thames and Hudson: London, 2003.

[14] Diller, E. \& Scofidio, R., Eyebeam Museum of Art and Technology. Metamorph - 9th International Architecture Exhibition, Trajectories, Venice Biennale, Rizzoli: New York, p. 262, 2004.

[15] Hadid, Z., The Centre of Contemporary Arts, Rome. http://www.designboom.com/portrait/ zaha_r.html.

[16] Gausa, M., Blobs. The Metapolis Dictionary of Advanced Architecture: City, Technology and Society in the Information Age, ACTAR: Barcelona, p. 84, 2003

[17] NOX, Wood EXPO, Zeeland, The Netherlands. Metamorph - 9th International Architecture Exhibition, Trajectories, Venice Biennale, Rizzoli: New York, p. 257, 2004.

[18] Gehry, F., Walt Disney Concert Hall, Los Angeles. Metamorph - 9th International Architecture Exhibition, Trajectories, Venice Biennale, Rizzoli: New York, pp. 76-77, 2004.

[19] Skidmore, Owings \& Merrill, Jinling Tower, Nanjing, China. Metamorph - 9th International Architecture Exhibition, Trajectories, Venice Biennale, Rizzoli: New York, p. 247, 2004.

[20] Forster, K., Hyper-projects. Metamorph - 9th International Architecture Exhibition, Trajectories, Venice Biennale, Rizzoli: New York, p. 341, 2004.

[21] Eisenman, P., Max Reinhardt Haus, Berlin. Metamorph - 9th International Architecture Exhibition, Trajectories, Venice Biennale, Rizzoli: New York, p. 252, 2004.

[22] Moussavi, F. \& Zaera, A., Complexity and consistency. El Croquis, 115/116, p. 31, 2003.

[23] UN Studio-Van Berkel \& Bos., Urban master plan, station area Arnhem Central, The Netherlands. Metamorph - 9th International Architecture Exhibition, Trajectories, Venice Biennale, Rizzoli: New York, p. 349, 2004.

[24] Himmelblau, C., Musee des Confluences, Lyon, France. Metamorph - 9th International Architecture Exhibition, Trajectories, Venice Biennale, Rizzoli: New York, p. 247, 2004.

[25] Papadopoulos, L., The diagram. Digital Topographies, ed. S. Papadimitriou, Futura Publications: Athens, p. 24, 2005.

[26] Deleuse, G., The Fold: Leibniz and the Baroque, Minnesota University Press: Minneapolis, MN, 1993.

[27] Spiller, N., Architectural futures. Digital Topographies, ed. S. Papadimitriou, Futura Publications: Athens, pp. 33-34, 2005. 